\title{
Impacts of global warming on changes in the East Asian monsoon and the related river discharge in a global time-slice experiment
}

\author{
Cholaw Bueh ${ }^{1}$, Ulrich Cubasch ${ }^{2, *}$, Stefan Hagemann ${ }^{3}$ \\ ${ }^{1}$ LASG, Institute of Atmospheric Physics, Chinese Academy of Sciences, Beijing, 100029, China \\ ${ }^{2}$ Meteorologisches Institut der Freien Universität Berlin, Care-Heinrich-Becker Weg 6-10, 12165 Berlin, Germany \\ ${ }^{3}$ Max Planck Institute for Meteorology, Bundesstr. 55, 20146 Hamburg, Germany
}

\begin{abstract}
Changes in the East Asian monsoon and the related river discharge under global warming conditions are investigated using 2 time-slice simulations of the IS92a scenario with a T106 atmospheric general circulation model (ECHAM4) for 1971 to 1980 and 2041 to 2050. Daily runoff and drainage calculated by the land-surface scheme are used as input to a hydrological model to diagnose changes in the Yangtze River and Zhujiang River discharges. In the future climate, the simulated annual cycle of precipitation over the southeastern coastal area of China is systematically shifted about 1 mo ahead compared with the present-day climate, and the rainy season starts 1 mo earlier for the Yangtze River Valley and North China. In line with the surface-warming distribution change, the East Asian summer monsoon (EAM) flow strengthens. This causes increased precipitation in North China. In winter, the subtropical part of the EAM flow strengthens and leads to a large increase in rainfall over the EAM region. The discharges of the Zhujiang and Yangtze rivers in the future climate decrease in the late summer and autumn, to which both increased evaporation and an early retreat of the monsoon rainfall contribute. In the early and mid-summer, the Yangtze River discharge increases, mainly due to the large increase in precipitation in the preceding months, which has been stored in the catchment.
\end{abstract}

KEY WORDS: Global warning · East Asian monsoon · Time-slice experiment · River discharge

\section{INTRODUCTION}

The warming associated with increasing greenhouse gas concentrations is likely to cause an increase in Asian summer monsoon precipitation variability (Kitoh et al. 1997, Hu et al. 2000a). The Asian monsoon is comprised of 2 distinctive entities: the South Asian (Indian) monsoon and the East Asian monsoon (EAM). This paper will focus on the change in the EAM under global warming conditions.

The EAM has complex space and time structures that are distinct from those of the South Asian (Indian) monsoon. Its rainy season (May to August, depending on the area) is characterized by persistence and northward movement of a zonally oriented rain band called
Meiyu. As discussed by Tao \& Chen (1987), the major components of EAM circulation that form Meiyu are the western Pacific subtropical high (WPSH), the crossequatorial flow of the lower atmosphere over the South China Sea and Bay of Bengal, and the mid-latitude baroclinic disturbances.

The EAM circulation and, in particular, its precipitation are affected by processes on spatial scales that are considerably smaller than those resolved in the coupled climate models currently employed. The resolution of the ECHAM4 atmospheric general circulation model (AGCM) used in $\mathrm{Hu}$ et al. (2000a), for instance, is only T42 $\left(2.8^{\circ} \times 2.8^{\circ}\right)$. With this resolution the model is too coarse to capture the EAM circulation and the related hydrological cycle adequately. Cur- 
rently, 3 techniques are available to compensate for this problem:

- dynamical downscaling via time-slice simulations with global high-resolution models;

- dynamical downscaling using high-resolution regional models;

- statistical downscaling.

The advantages and limitations of these methods have been discussed in Cubasch et al. (1995), Lal et al. (1997), Rummukainen (1997) and IPCC (2001). In this study, we employ the time-slice simulation method (Bengtsson et al. 1995, Cubasch et al. 1996, Wilby \& Wigley 1997, Déqué et al. 1998, Jones et al. 1998, May \& Roeckner 2001), which uses a global atmosphere model with a horizontal resolution of $1.1^{\circ} \times 1.1^{\circ}$. Details of the model and the design of the time-slice experiments can be found in Section 2 .

The present-day interannual and interdecadal variability of the EAM have been extensively studied by many investigators (Ding 1991, Yasunari 1991, Lau 1992, Nitta \& Hu 1996, Ji et al. 1997, Chen \& Graf 1998, Bueh \& Ji 1999a, Lu \& Chan 1999, Samel et al. 1999, Kripalani \& Kulkarni 2001). However, the EAM change under global warming conditions has hardly been investigated. Wang \& Ye (1993) and Nitta \& Hu (1996) found from observational data a pronounced warming trend in North China.

Using observational data, Hulme et al. (1994) concluded that coinciding with warming in the last century, East Asian precipitation increased with a trend of $0.54 \%$ decade $^{-1}$, which is larger than the global average for land areas $\left(0.25 \%\right.$ decade $\left.^{-1}\right)$. Analyzing model simulations, they further suggested that by 2050 the mean temperatures of East Asia will be higher than the warm seasonal anomalies that occurred during the last decade. The mean annual precipitation is projected to increase by about $3 \%$, but with greater uncertainty than for the temperature projection.

Signs of intensified Asian summer monsoon and weakened East Asian winter monsoon have been derived from the long-term output of a coupled atmosphere-ocean model (Hu et al. 2000a,b). The impact of the global warming on the EAM annual cycle will be investigated in section 3.

The discharges of the Yangtze and Zhujiang rivers are closely related to the EAM precipitation. Since the 1990s, the Yangtze River has shown a tendency towards more frequent and greater flooding. Chinese researchers have attributed this partly to the impact of increasing atmospheric concentrations of greenhouse gases. An analysis of changes in the discharge of the Yangtze and Zhujiang rivers is performed in Section 4, followed by a summary and discussion in Section 5.

\section{MODEL, TIME-SLICE EXPERIMENT AND DATA}

The time-slice experiments used the ECHAM4 AGCM, developed at the Max Planck Institute for Meteorology, for simulating the present-day and future global climate. It employs a 19-level hybrid sigma-pressure coordinate system, which extends vertically up to a pressure level of $10 \mathrm{hPa}$. The prognostic variables are represented by spherical harmonics with triangular truncation at wavenumber 106 (T106). Compared to its T42 resolution model, the high-resolution model produces in many respects a more realistic simulation of the present-day climate due to the inclusion of a much wider spectrum of spatial scales, and hence the interactions among them, and a more realistic representation of the topography (Stendel \& Roeckner 1998). However, a number of problems remain since, due to restrictions of computing resources, the T106 model could not be tuned optimally (Roeckner et al. 1996).

Two 10 yr simulations with this high-resolution model were performed as so-called time-slice experiments. One represents the present-day climate, while the other a climate with a doubled atmospheric concentration of $\mathrm{CO}_{2}$. For the first time-slice simulation, which covers 1971 to 1980, the lower boundary forcing i.e. monthly mean values of the sea-surface temperatures (SSTs) and of the sea ice extent and thickness was prescribed from a transient climate-change simulation performed with a coupled atmosphere-ocean model (ECHAM4/OPYC3) at T42 resolution, which extended from 1860 to 2050. For the second simulation of future climate, corresponding to the period 2041 to 2050 , the changes in the lower boundary forcing were obtained from the same transient climate-change experiment. The data were detrended in order to mimic an equilibrium simulation with a mixed-layer model. The atmospheric concentrations of various gases for both time-slice experiments are prescribed as the corresponding 10 yr means.

The coupled model simulation, from which the boundary forcing was derived, is 1 of 3 time-dependent forcing experiments described by Roeckner et al. (1999), and referred to as 'GHG' in their work. In the simulation, the concentrations of various greenhouse gases were prescribed as a function of time: $\mathrm{CO}_{2} \mathrm{CH}_{4}$; $\mathrm{N}_{2} \mathrm{O}$; CFC-11, -12, -113, -114, -115; HCFC-22, -123, $-141 \mathrm{~b} ; \mathrm{HFC}-125,-134 \mathrm{a},-152 \mathrm{a} ; \mathrm{CCl}_{4} ;$ and $\mathrm{CH}_{3} \mathrm{CCl}_{3}$. From 1990 onward, which contains the second period of our second time-slice simulation, the annual mean concentrations of these gases were prescribed according to the modified IPCC scenario IS92a ('IS95a'; Houghton et al. 1996). Details of this model can be found in Roeckner et al. (1996), Bacher et al. (1998) and the EU-project report SIDDACLICH (Simulation, 
Diagnosis and Detection of Anthropogenic Climate Change; Cubasch et al. 2000).

The monthly mean precipitation and surface air temperature data of the Climatic Research Unit (CRU; New et al. 2000) for 1971 to 1980 and the monthly mean $1000 \mathrm{hPa}$ wind of the National Center for Environmental Prediction (NCEP) reanalysis data (1971 to 1980; Kalnay et al. 1996) were used to validate the simulated values for the present-day climate. The observed monthly river discharges from Global Runoff Data Center (GRDC; Dümenil-Gates et al. 2000) were compared with the simulated present-day discharge.

To analyse the statistical significance of the changes, an optimal 2-sided test was applied (Lehmann 1986).

\section{CHANGE IN THE ANNUAL CYCLE}

The EAM rainfall is concentrated in the late spring and summer, and generally persists over South China and the Yangtze River. Its rainfall peaks also during summer, even though the amount is small. From late spring to summer, the EAM rain gradually moves northward and finally arrives in North China. We have selected 3 regions to represent the key areas related to the seasonal evolution of EAM circulation: the southeastern coastal area $\left(\mathrm{SEC}, 110-125^{\circ} \mathrm{E}, 20-27^{\circ} \mathrm{N}\right)$; the Yangtze River valley (YRV, $110-125^{\circ} \mathrm{E}$, $\left.27-34^{\circ} \mathrm{N}\right)_{i}$ and North China (NCN, $\left.110-125^{\circ} \mathrm{E}, 36-42^{\circ} \mathrm{N}\right)$. The geographical locations of these 3 regions are shown in Fig. 1.

Annual cycles of the area-mean $2 \mathrm{~m}$ temperature over the SEC, YRV and NCN are displayed in Fig. 2 (left). The annual cycles of the temperature for these regions are well simulated in the present-day climate simulation (first time-slice). However, in winter, the simulated $2 \mathrm{~m}$ temperatures are approximately 1 to $2^{\circ} \mathrm{C}$ lower than the surface air temperatures of the CRU data for all 3 regions. In addition, the simulated summertime temperature of $\mathrm{NCN}$ is overestimated.

In most months, the temperature changes between the 2 time-slice simulations are significant at the $95 \%$ confidence level for all 3 regions (Fig. 2, right). However, the simulated temperature increase varies between seasons (Fig. 3). In winter and spring, the temperature change increases from the SEC

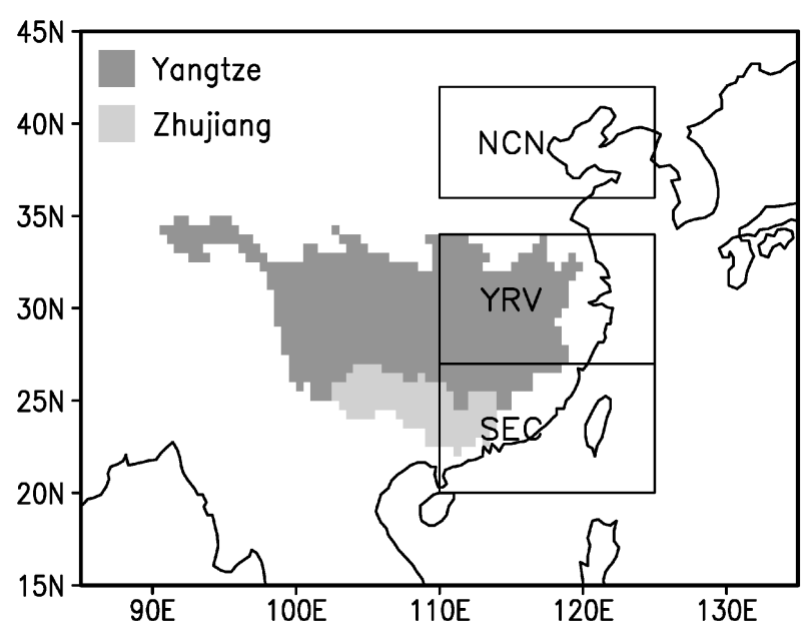

Fig. 1. Geographical locations of the SEC (southeastern coastal area), YRV (Yangtze River Valley) and NCN (North China) and the catchment areas of the Zhujiang and Yangtze rivers
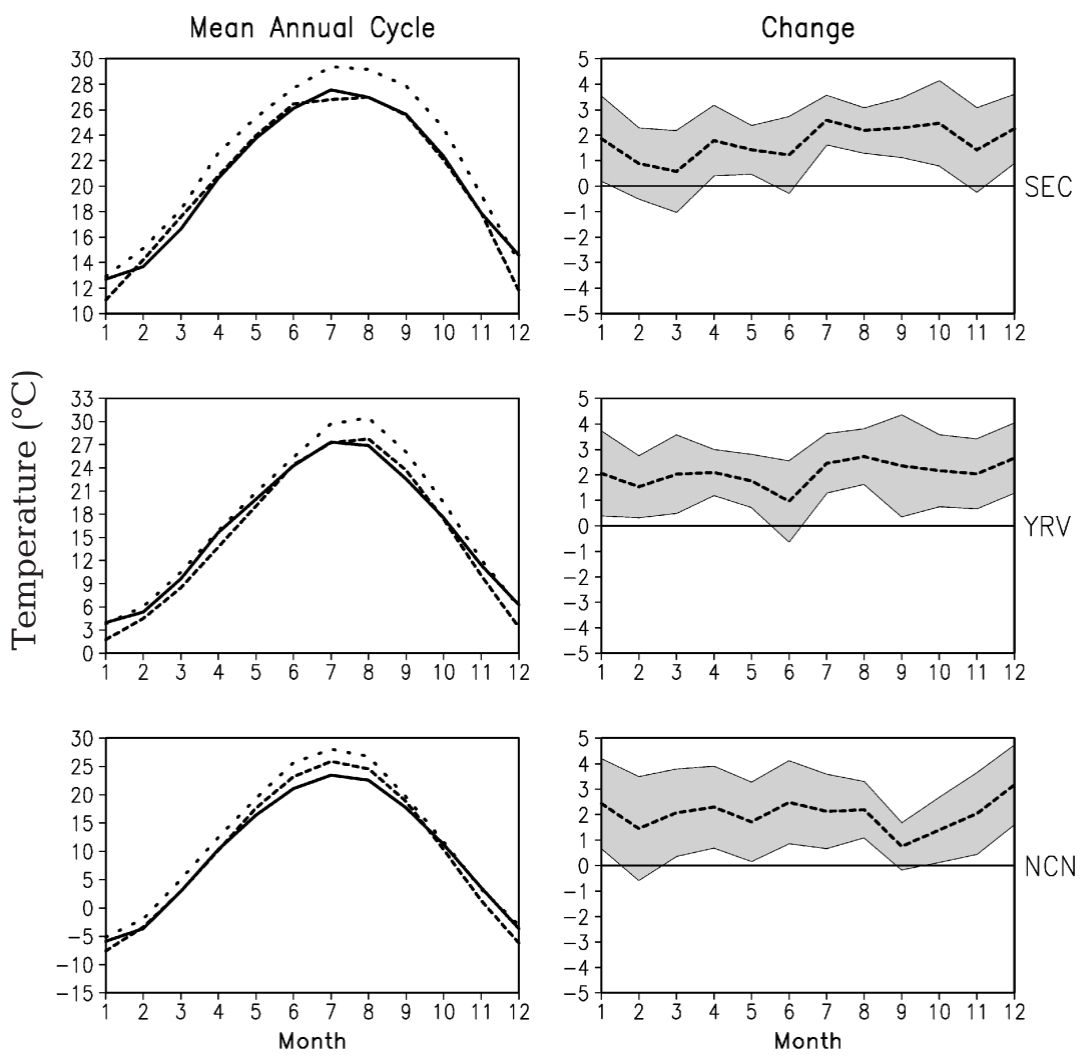

Fig. 2. (Left) Annual cycles of area-mean $2 \mathrm{~m}$ temperatures $\left({ }^{\circ} \mathrm{C}\right)$ in the 2 time-slice simulations and the surface air temperature from CRU data in the SEC, YRV and NCN. Solid line: CRU data; dashed and dotted lines are first and second time-slice simulations, respectively. (Right) Annual cycles of $2 \mathrm{~m}$ temperature changes $\left({ }^{\circ} \mathrm{C}\right.$ ) between the 2 time-slice simulations in the SEC, YRV and NCN. Shading and dashed line represent change in the $95 \%$ confidence level and mean, respectively 
(a) DJF

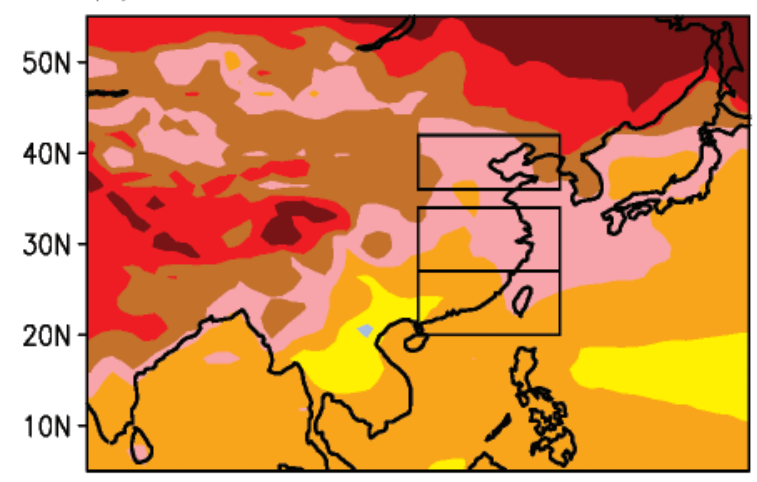

(c) JJA

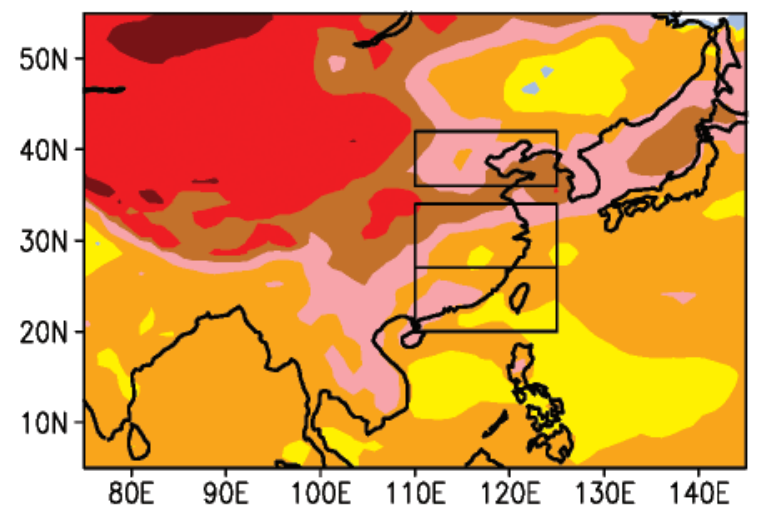

(b) MAM

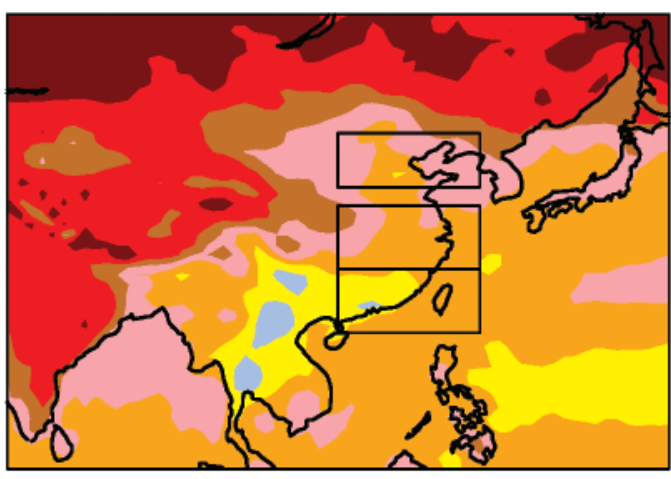

(d) SON

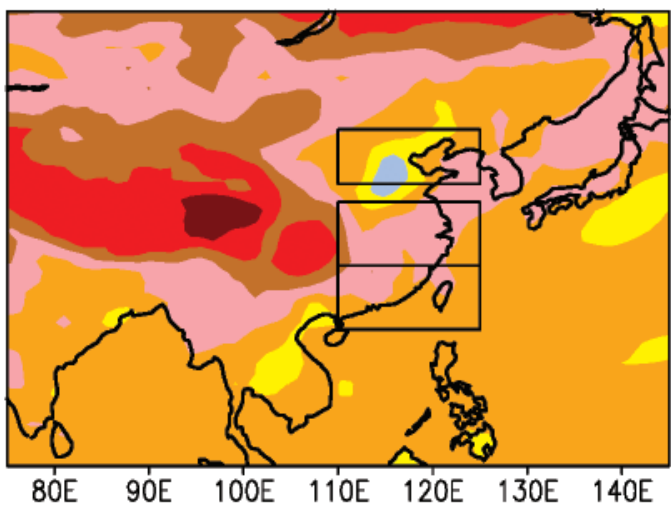

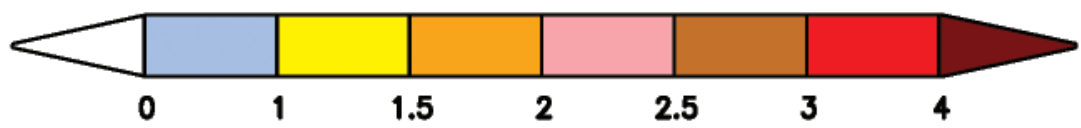

Fig. 3. Distributions of the mean $2 \mathrm{~m}$ temperature changes $\left({ }^{\circ} \mathrm{C}\right)$ for 2041 to 2050 in (a) winter, (b) spring, (c) summer, and (d) autumn. The 3 domains in the figure stand for the SEC, YRV and NCN. Units are ${ }^{\circ} \mathrm{C}$

via the YRV to the higher latitude region. This is consistent with the consensus conclusion of many IPCCrelated studies that the warming in higher latitudes is greater than that in the subtropics (e.g. IPCC 2001). However, this temperature pattern changes in summer and autumn. Specifically, a center of reduced temperature change $\left(<1.5^{\circ} \mathrm{C}\right)$ appears to the north of the NCN in summer and over the NCN as well as its north side in autumn. The spatially varying temperature increase in the EAM region and its adjacent oceans (i.e. the western Pacific covering the South China Sea and the East China Sea) implies a change in the landsea thermal contrast and hence a change in EAM circulation, since the variation of the western Pacific SST is closely related to that of the EAM circulation in different seasons (Huang \& Sun 1992, Bueh \& Ji 1999b).

In the lower troposphere, the zonal and meridional winds are of the same magnitude during the EAM. Therefore the meridional wind is taken to represent the EAM strength following suggestions by Ji et al.
(1997). The annual cycles of meridional winds at the $1000 \mathrm{hPa}$ level for the SEC, YRV and NCN are given in Fig. 4 (left). For the SEC region the annual cycle of the meridional wind is simulated well, while for the other 2 regions it is underestimated in winter. Compared to the NCEP reanalysis, over the SEC and YRV the northerly winds in winter are simulated to become stronger, and the southerly winds in summer are projected to become weaker. A stronger annual cycle is projected for NCN.

The changes of the annual cycles for the 3 regions are displayed in Fig. 4 (right). In late winter and early spring the flow from the north over the SEC is strengthened, implying an enhancement of the winter monsoon over this period, whereas there is a slight increase during the other months. The strong interannual fluctuation limits significance at the $95 \%$ level to February only. For the YRV, the annual cycle is strengthened for both the summer and late-winter monsoon flows. In February, the monsoon flow is 

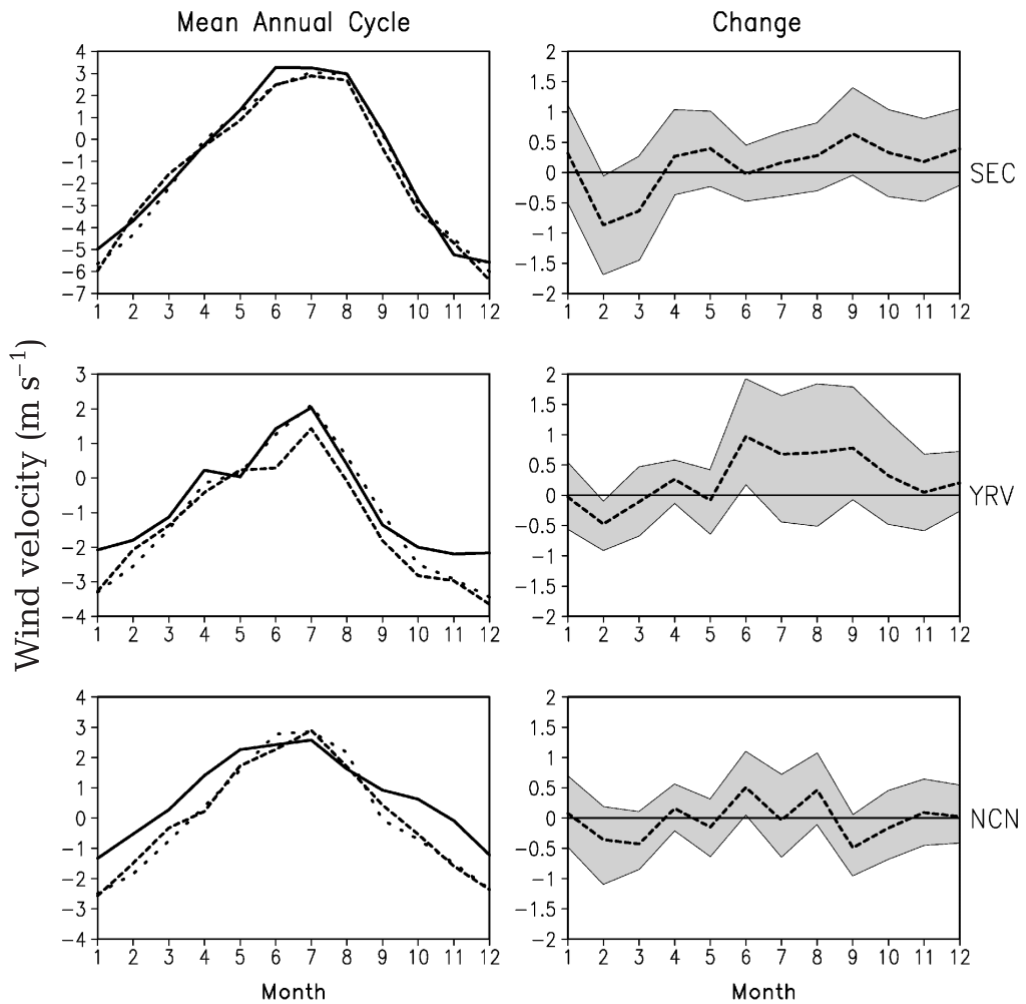

Fig. 4. As Fig. 2, but for area-mean meridional wind velocity $\left(\mathrm{m} \mathrm{s}^{-1}\right)$ at the $1000 \mathrm{hPa}$ level. Solid lines in left-hand panels are for NCEP Reanalysis

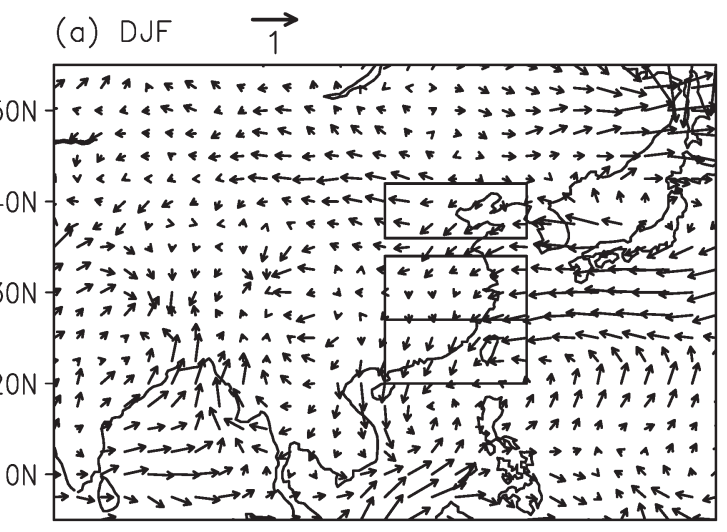

Fig. 5. As

Fig. 3, but for wind $\left(\mathrm{m} \mathrm{s}^{-1}\right)$ at the $1000 \mathrm{hPa}$ level enhanced in all 3 regions and, as a consequence, a homogeneous precipitation increase occurs in these regions (see Fig. 6). The change is significant at the $95 \%$ level only during February and June. Over NCN, the flow is only significantly (95\% level) enhanced during early summer.

The winter monsoon flow along the eastern border of the Asian continent is weakened between latitudes 38 and $50^{\circ} \mathrm{N}$ (Fig. 5a), whereas it is enhanced to the south of this latitude band. The mid-latitude part of the winter monsoon flow is weakened or shifted eastward as the subtropical part strengthens significantly. Another prominent feature related to the winter monsoon flow is the anomalous cyclonic convergence, and thus the moisture convergence, over the YRV, the SEC, and the South China Sea. This implies a precipitation increase over these regions.

The EAM precipitation is influenced by 3 distinct but interactive systems: a tropical monsoon that mainly consists of southerly flow over the Bay of Bengal and South China Sea, the WPSH, and the mid-latitude baroclinic disturbances. In particular, the position and seasonal movement of the WPSH have a crucial effect on the EAM rain band (Chang

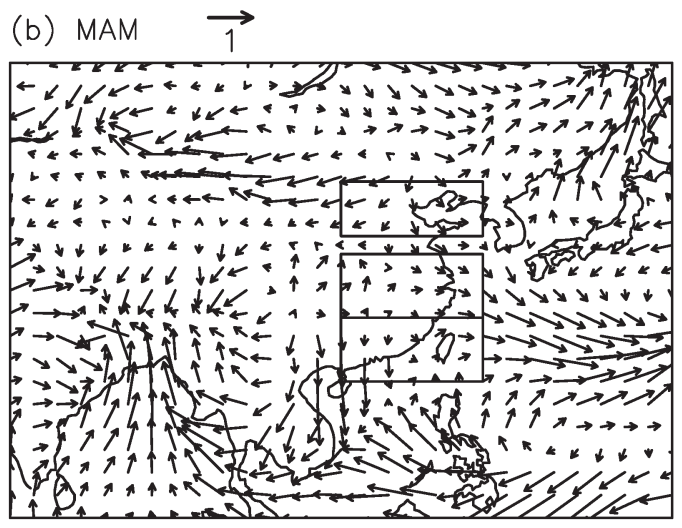

(d) $\operatorname{SON} \quad \overrightarrow{2}$

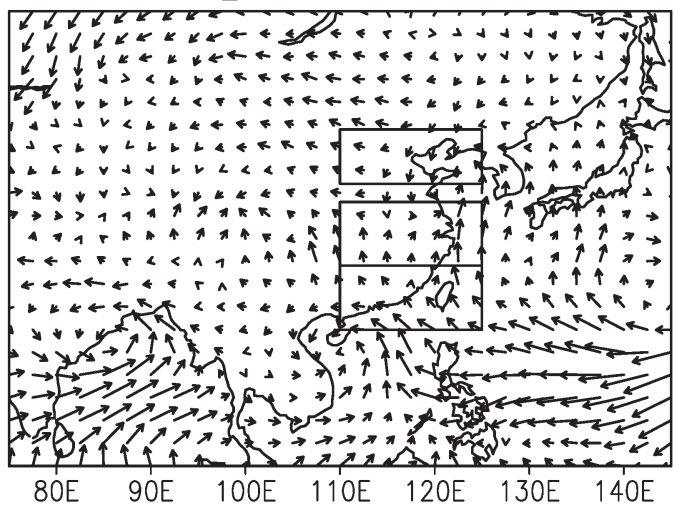


et al. 2000). Our model captures the coarse large-scale features of the seasonal evolution of the EAM precipitation (Fig. 6, left). For SEC, the seasonal evolution is well simulated, but the precipitation amounts in May and June are lower than the observed amounts, mainly because the simulated WPSH shifts eastwards in spring and summer compared to the NCEP reanalysis (figure not shown). For the same reason, the YRV rainfall peak appears too early. For NCN, the annual cycle of precipitation is underestimated and the simulated summer rainfall peak is smaller than in the observations.

The simulated annual cycle of the SEC precipitation in the future climate systematically shifts about 1 mo ahead of that of the present-day climate (Fig. 6, top left). Consequently, the rainy season of the SEC both begins and ends 1 mo early. The precipitation increases from mid-winter to mid-summer, and it decreases during late summer and early autumn. These changes are significant at the 95\% level in January, February, August and September.

For the YRV, the onset of the rainy season is simulated to appear 1 mo earlier in the future climate than in the present-day climate (Fig. 6, middle left). The winter and early spring precipitation increases, while it remains unaltered during the other seasons. The
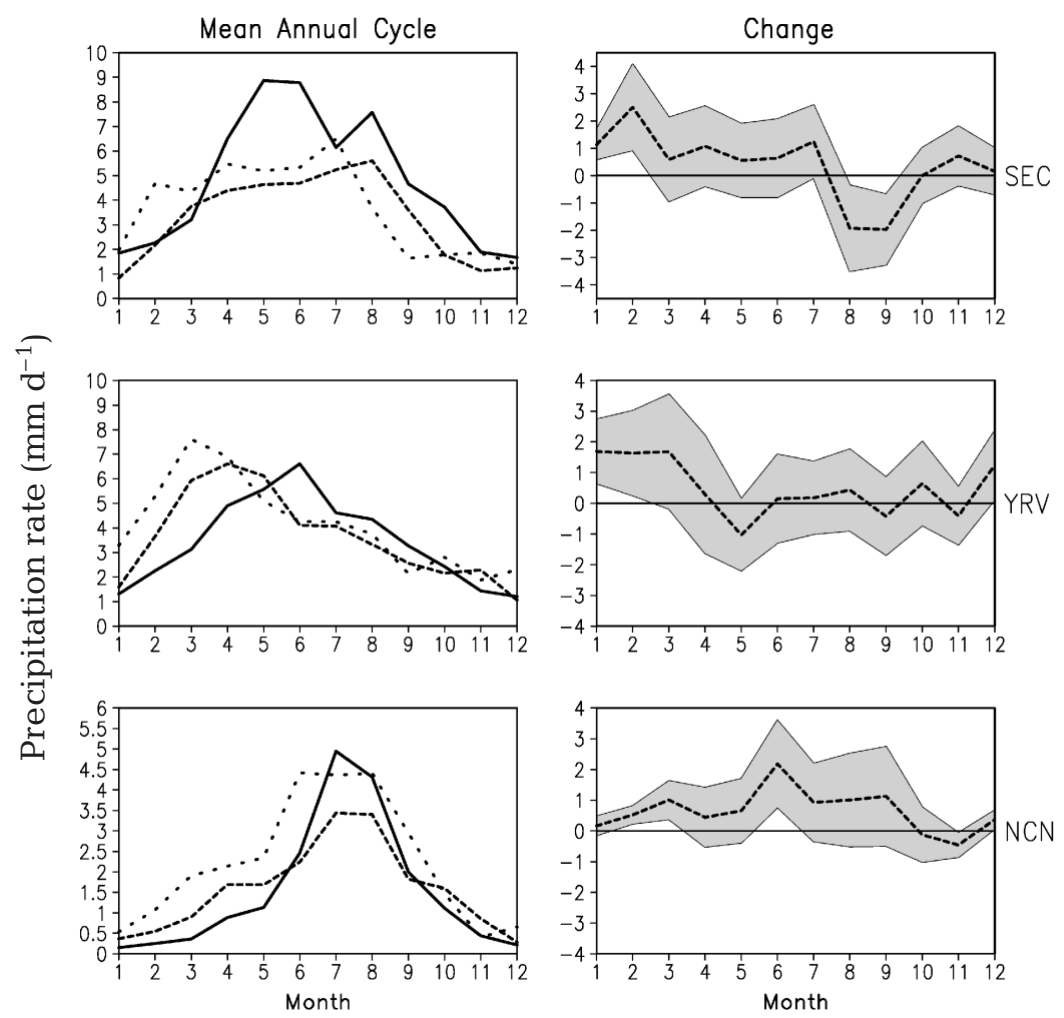

Fig. 6. As Fig. 2, but for area-mean precipitation rate $\left(\mathrm{mm} \mathrm{d}^{-1}\right)$ change in winter is significant. The onset time of the summer monsoon flow is not changed (Fig. 4, top and middle left). Therefore, the early onset of the rainy season in the SEC and YRV results from the surface warming, the increased moisture, and the intensified winter monsoon flow. For NCN, the simulated rainfall peaks in the future climate 1 mo earlier (Fig. 6, bottom left). The rainfall increases from February to September. This change is significant at the $95 \%$ level only in February, March and June.

In the coupled GCM simulation, from which the boundary forcing of our time-slice simulation is derived, $\mathrm{Hu}$ et al. (2000b) found for 2041 to 2050 a weakened Asian winter monsoon circulation. An anomalous cyclonic convergence with a center in the western Pacific can be found at the low resolution they used (Hu et al. 2000b, their Fig. 1d,e) and at the high resolution we used (Fig. 5a) in the simulation, but with the difference that in our case the anomalous cyclonic convergence extends westward to the eastern continent of China, i.e. the YRV and SEC. This results in the enhancement of monsoon flow in our study.

In $\mathrm{Hu}$ et al. 2000b, the monsoon flow is separated from the anomalous southerly flow over the YRV and SEC. Here the anomalous cyclone over the western Pacific is related to the enhancement of the Asian winter monsoon flow between 32 and $40^{\circ} \mathrm{N}$ during the first years of the simulation (2000 to 2049, their Fig. 1d). The connection with the Asian winter monsoon disappears and the anomalous southerly flow dominates over the whole EAM region in the later years of the projection (2050 to 2099, their Fig. 1e). Both the change in the local land-sea thermal contrast (between the continent and the adjacent sea) and that of the circulation over the western Pacific contribute to the change in the wintertime EAM circulation. This last effect becomes increasingly important in the later phases of the climate projection. In our study, the anomalous cyclonic convergence over the western Pacific is responsible for strengthening the monsoon flow over the YRV and SEC. The different changes in the winter monsoon flow in the 2 studies lead to different precipitation changes. In winter, a large rainfall increase is simulated in the YRV and SEC in our study, while in Hu et al. (2000b) it occurs in an area extending from the northern part of the YRV to the southern part of North China.

In summer, in line with the surfacewarming distribution, the monsoon flow strengthens along the East Asian coast (Fig. 5c). The anomalous monsoon flow is 
divergent over the SEC and the YRV and convergent in the NCN. The flow pattern does lead to increased precipitation over the SEC and YRV (Chang et al. 2000), and to a northward intrusion of the precipitation band into North China (Fig. 7c). Thus, in the East Asian region, the summer rainfall increase in NCN stands out, compared to that in the SEC and YRV.

\section{CHANGE IN RIVER DISCHARGE}

In order to study the changes in discharge of the rivers in the EAM region, i.e. the Zhujiang and Yangtze rivers, a global hydrological discharge model developed by Hagemann \& Dümenil (1998) was applied. The model describes the translation and retention of the lateral discharge as a function of the spatially distributed land-surface characteristics. This model separates the lateral water flow into 3 flow processes: overland flow, base flow, and river flow. Overland flow and base flow are both represented by a single linear reservoir, and river flow is represented by

(a) DJF

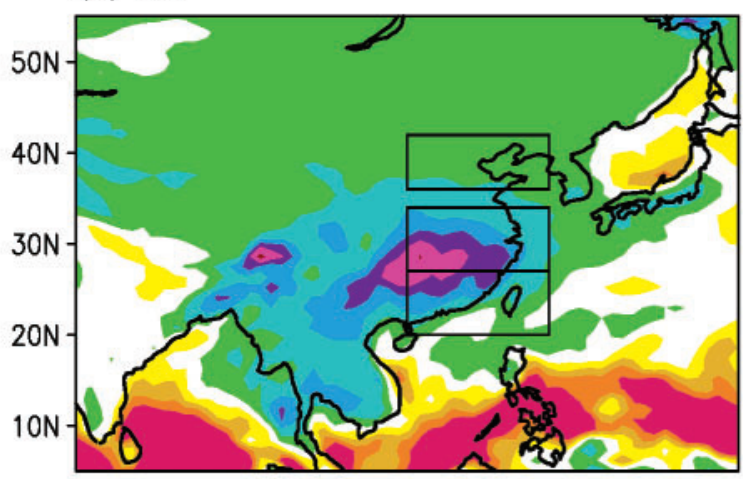

(c) JJA

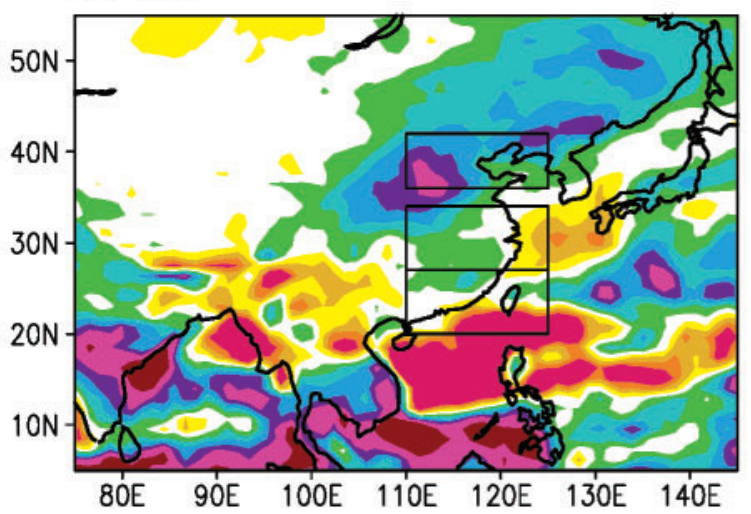

a cascade of linear reservoirs. The overland flow uses runoff as input, the base flow is fed by drainage, and the inflow from other grid boxes contributes to the river flow. The sum of the 3 flow processes equals the outflow from a grid box. The discharge of a river is equivalent to the outflow from the river mouth to the ocean. The model computes the discharge at a $0.5^{\circ} \times 0.5^{\circ} \mathrm{spa}$ tial resolution and a daily time step. Anthropogenic impacts, such as dams, reservoirs and irrigation, are not considered in the model. The performance of the hydrological discharge model is described in Hagemann \& Dümenil (1998) for the global scale and in Hagemann \& Dümenil (1999) for the Baltic Sea region.

The surface runoff and drainage from the soil, which are used as the input fields to the hydrological discharge model, are not directly available from the 2 time-slice simulations discussed in the previous section. Thus, daily time series were calculated from the corresponding precipitation and $2 \mathrm{~m}$ temperature data using a simplified land-surface scheme (Hagemann \& Dümenil 1998). This scheme computes the total water balance at the land surface, including soil moisture,

\section{(b) MAM}

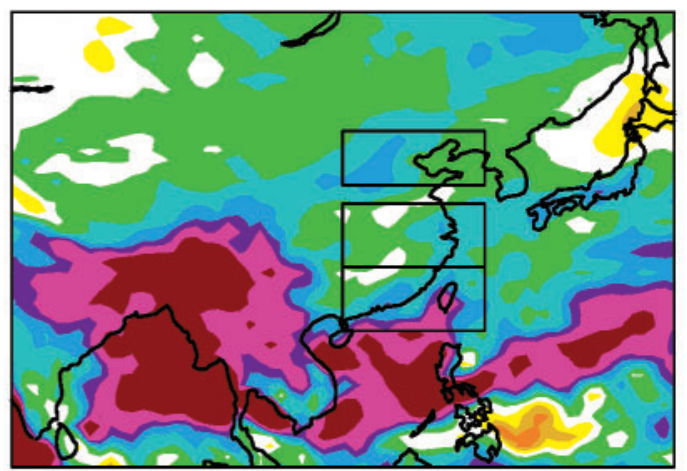

\section{(d) SON}

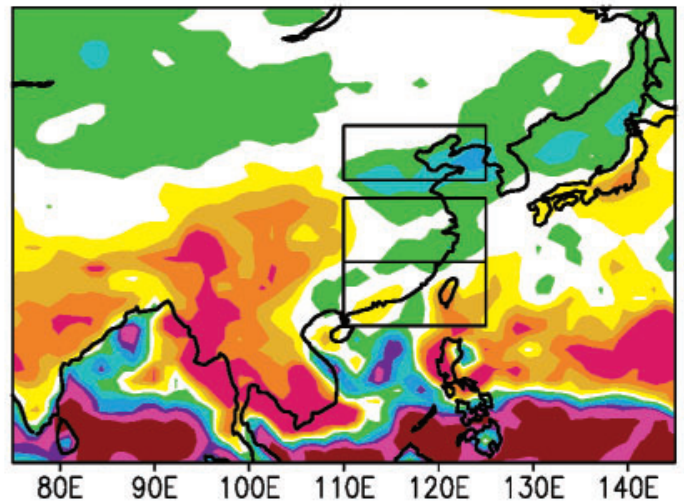

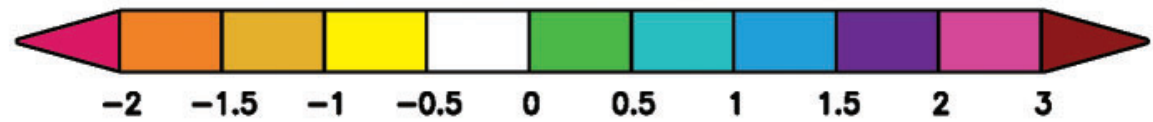

Fig. 7. As Fig. 3, but for precipitation rate $\left(\mathrm{mm} \mathrm{d}^{-1}\right)$ 
accumulation of snow, snowmelt, evapotranspiration, runoff, and drainage. It has been applied to validate the hydrological cycles in the European Center for Medium-Range Weather Forecasts (ECMWF) and NCEP reanalyses, and it has been shown to be a good tool for representing the land-surface water balance (Hagemann \& Dümenil-Gates 2001).

The catchments of the Zhujiang and Yangtze rivers are displayed in Fig. 1. It can be seen that the SEC and YRV coincide with the eastern parts of the Zhujiang and Yangtze river catchments respectively. The changes in the EAM flow and the related rainfall in the SEC and YRV, which are analyzed in the previous section, are therefore a good reference for the discharge analysis of the corresponding rivers.

Compared to the corresponding GRDC data, the seasonal evolutions of the discharges of the Zhujiang and Yangtze river catchments are reasonably well simulated (Fig. 8). From May to September, the simulated discharge of the Zhujiang River is lower than the observed one. That of the Yangtze River is higher than the observations during the entire year. The simulated error for the Zhujiang River catchment is mainly caused by the simulated precipitation bias during the warmer months (Fig. 6, top left). This can also be found for the Yangtze River catchment from January to May (Fig. 8, bottom left). According to the GRDC data, the discharges of the 2 rivers reach their peak amounts about 1 mo later than that of the corresponding monsoon precipitation, reflecting the characteristic retention time (or coefficient) of the catchments. It can clearly be seen from Figs. 6 $\& 8$ that the simulated bias of the precipitation in the time-slice simulation is also transferred into that of the river discharge.

In the Zhujiang River catchment, the simulated future climate discharge decreases in the second half year. The change is significant at the $95 \%$ level from October to December, while no clear signal is found in the first half of the year. The reduced precipitation (Fig. 6, top left), for which the early monsoon retreat is responsible, together with increased evaporation caused by the surface warming (Fig. 9), decreases the discharge during the second half of the year. The evaporation increase in this catchment is significant in most months of the second half year, consistent with surface warming (Fig. 3). It is noteworthy that the precipitation increase from January to April leaves
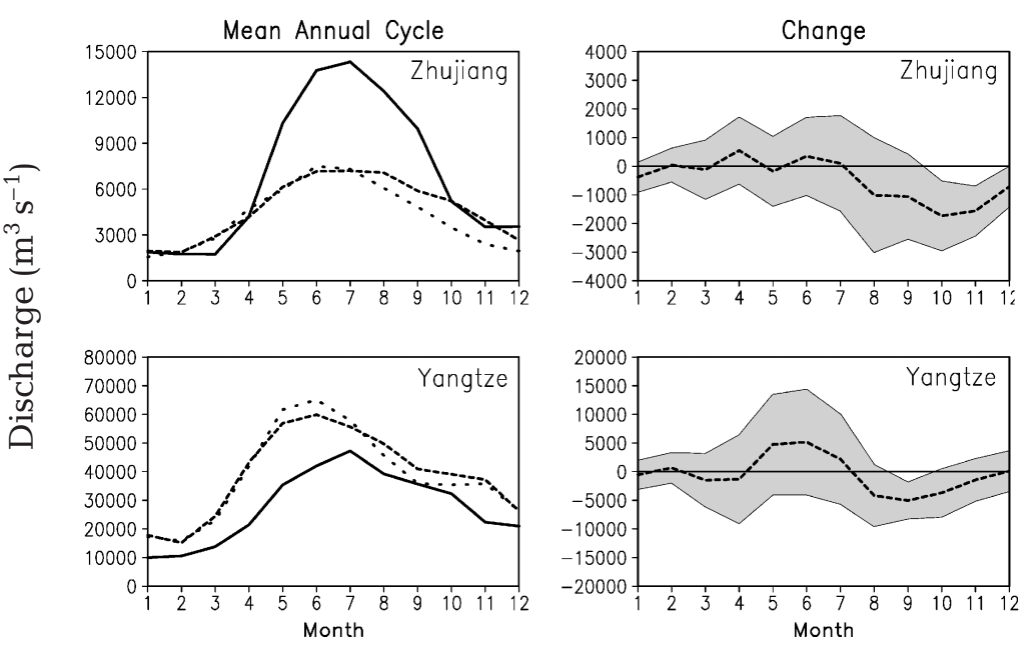

Fig. 8. (Left) Annual cycles of the Zhujiang and Yangtze river mean discharges $\left(\mathrm{m}^{3} \mathrm{~s}^{-1}\right)$ for the 2 time-slice simulations and GRDC data. Solid line: GRDC data; dashed and dotted lines are first and second time-slice simulations, respectively. (Right) Annual cycles of the discharge changes $\left(\mathrm{m}^{3} \mathrm{~s}^{-1}\right)$ between the 2 time-slice simulations in the Zhujiang and Yangtze river catchments. Shading and dashed

line indicate change in the $95 \%$ confidence level and mean, respectively
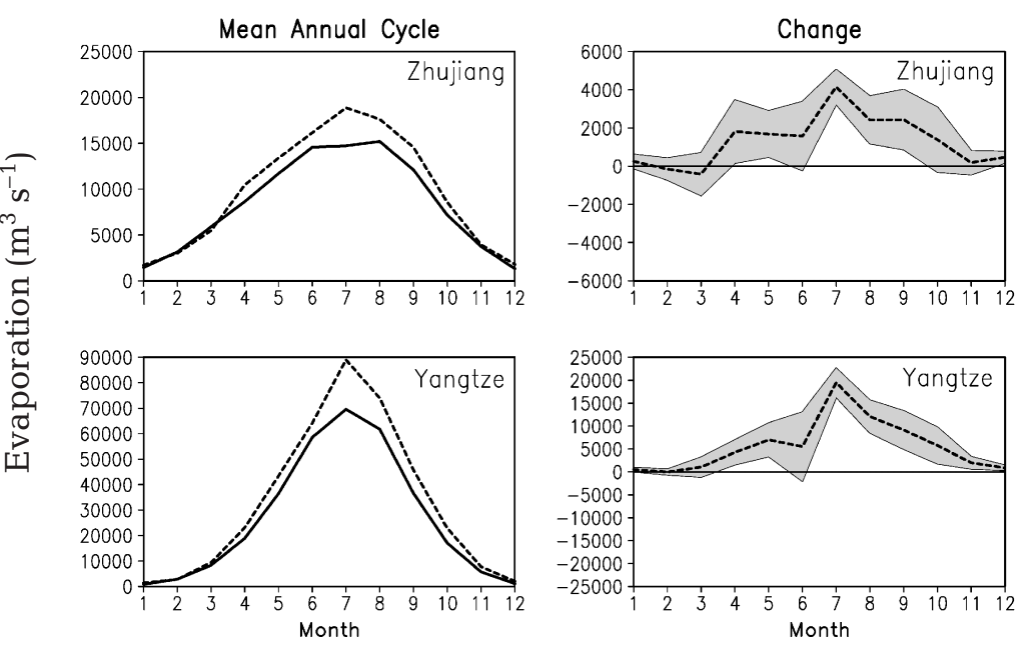

Fig. 9. As Fig. 8, but for monthly mean evaporation. Solid and dashed lines in the left-hand panels are for the first and second time-slice simulations; there is no observational data drawn in the left-hand panels

the corresponding discharge unchanged. Its increase in the Zhujiang River catchment during winter and spring is saved in the soil layers in early and midspring due to the characteristic retention time of the catchment. From May to July the discharge decreases slightly due to the increase in catchment evaporation, while during this time the precipitation changes only marginally.

The simulated discharge under doubled $\mathrm{CO}_{2}$ in the Yangtze River catchment increases in May and June and decreases from August to October (Fig. 9). Only in September does this decrease become significant; dur- 
ing the other months the strong interannual variability masks any signal. The increased discharge in May and June despite the decreased precipitation is caused by the precipitation increase in winter and spring (Fig. 6, middle): The increased amounts of precipitation in winter and in early and mid-spring are stored in the soil layers of the catchment and in the land surface as the snow pack (figure not shown), especially over the eastern slopes of the Tibetan plateau. This results in increased discharge during May and June. Additionally, the evaporation increases in May and June (Fig. 9). From August to October, the discharge decrease is caused by both the early retreat of the monsoon rainfall and the strong evaporation increase (Fig. 9 bottom).

\section{SUMMARY AND DISCUSSION}

In this study, the changes of the EAM and the related river discharge under global warming conditions $\left(\mathrm{CO}_{2}\right.$ doubling) are investigated using 2 time-slice simulations with an atmospheric general circulation model, ECHAM4 AGCM (T106), and a hydrological discharge model. The first time-slice simulation (1971 to 1980) represents the present-day climate and the second simulation (2041 to 2050) the mid-21st-Century climate. The daily output data of runoff and drainage corresponding to these 2 simulations are calculated using a simplified land-surface scheme and used as the input to the hydrological discharge model for simulating the discharge changes of the Yangtze and Zhujiang river catchments.

In the EAM region, the distribution of the mean surface temperature change simulated in the mid-21stCentury climate ranges from 1.0 to $2.5^{\circ} \mathrm{C}$, and it is very similar to the simulated range $\left(1.0\right.$ to $\left.3.0^{\circ} \mathrm{C}\right)$ of the multi-model ensemble based on the IS92a (G: greenhouse gases only) scenario over the same region (IPCC 2001). The corresponding annual mean precipitation change ranges from 5 to $20 \%$ in the SEC and YRV, which agrees with the same multi-model ensemble (IPCC 2001) and amounts to more than $50 \%$ in the NCN, which is substantially higher. This difference results from the greater increase in winter and earlyspring precipitation in this study compared to the IPCC multi-model ensemble.

The simulated annual cycle of the SEC precipitation in the mid-21st-Century climate systematically peaks about 1 mo earlier than in the present-day climate. For the YRV and NCN precipitation, the onset of the rainy season will start 1 mo earlier in the future climate than in the present-day climate. The subtropical part of the EAM flow strengthens significantly in winter, whereas its mid-latitude part is weakened or shifted eastward in the future climate. The strengthened part of the winter monsoon flow is closely associated with the anomalous cyclonic convergence over the YRV, SEC and South China Sea; thus, it leads to the strong rainfall increase over the EAM region. In summer, in line with the surface warming distribution, the monsoon flow strengthens along the East Asian coast. This results in increased precipitation over North China in the future climate. The discharges of the Zhujiang and Yangtze rivers in the future climate decrease in late summer and autumn, to which both the increased evaporation and the early retreat of the monsoon rainfall contribute. In early and mid-summer, in contrast to the situation for the Zhujiang River catchment, the discharge of the Yangtze River catchment increases, mainly due to the strong increase in precipitation in the preceding months, which is stored as snow or groundwater in the catchment region.

We are trying to capture more detailed information on the EAM circulation and precipitation in the highresolution model but, because of limited computer resources, only two $10 \mathrm{yr}$ time-slice simulation data are presently available to us. However, the $10 \mathrm{yr}$ simulation period seems short and not capable of catching the signals of longer than decadal time-scales, which are likely to distort the results obtained in this study. Thus, efforts towards obtaining longer time-slice experiments will help to address this issue. According to the observational and proxy data from 1880 to 1990, Wang et al. (2001) found that a warm-wet relationship exists over the SEC and part of the YRV, while it is a warmdry relationship over North China and part of the YRV, in contrast to our results. Despite this, our results suggest that there is no robust connection between global warming and the more frequent flooding of the Yangtze River Valley, consistent with the conclusion of Wang et al. (2001).

In addition, it can be seen in Fig. 6 (top and middle left) that the model used here, like other AGCMs currently available, is not able to simulate the seasonal evolution of the EAM precipitation with great reliability. Thus, further improvement of the model in representing the EAM cycle is necessary.

Another limitation of this study is that anthropogenic aerosols are not taken into account in the future climate simulation. Studies by Lal et al. $(1996,1997)$ and recent studies based on the IPCC Special Report on Emissions Scenarios (SRES) indicate that anthropogenic aerosols act as a net negative radiative forcing in the future climate change (IPCC 2001). Roeckner et al. (1999) argued that the enhancement of the Indian monsoon and the EAM (see their Fig. 16a-c) is not fundamentally affected by the inclusion of aerosols. However, the differences between the high- and low-resolution models, and uncertainties in the spatial distribution of aerosols, leave the effect of aerosols on the EAM undetermined. 
Acknowledgements. The first author thanks the Max Planck Institute for Meteorology (MPIM) and the Max Planck Gesellschaft for their support during his stay in Hamburg. This work is supported by the BMBF project (MBG002-7), Key Project of the Chinese Academy of Sciences (ZKCX2-SW-210) and National Key Programme for Developing Basic Sciences (G1998040904). The experiments were performed under the EU project SIDDACLICH (ENV4-CT95-0102). The authors are indebted to J. Wegner, H.-H. Winter, V. Gayler, E. Röckner, U. Schlese, H. Thiemann and other colleagues at MPIM for their help with data processing, graphic programming and helpful discussion. The first author is grateful to Ji Liren, Wu Guoxiong and Huang Ronghui for their encouragement.

\section{LITERATURE CITED}

Bacher A, Oberhuber JM, Roeckner E (1998) ENSO dynamics and seasonal cycle in the tropical Pacific as simulated by the ECHAM4/OPYC3 coupled general circulation model. Clim Dyn 14:431-450

Bengtsson L, Botzet M, Esch M (1995) Hurricane-type vortices in a general circulation model. Tellus 47A:175-196

Bueh C, Ji L (1999a) Anomalous activity of East Asian winter monsoon and the tropical Pacific SSTA. Chin Sci Bull 44:890-898

Bueh C, Ji L (1999b) The ocean-atmosphere coupled regimes and East Asian winter monsoon (EAWM) activity. Adv Atmos Sci 16:91-106

Chang CP, Zhang Y, Li T (2000) Interannual and interdecadal variations of East Asian summer monsoon and tropical Pacific SSTs. Part I: Roles of the subtropical ridge. J Clim 13:4310-4325

Chen W, Graf HF (1998) The interannual variability of East Asian winter monsoon and its relation to global circulation. Adv Atmos Sci 17:48-60

Cubasch U, Waskewitz J, Hegerl G, Perlwitz J (1995) Regional climate changes as simulated in time-slice experiments. Clim Change 31:273-304

Cubasch U, von Storch H, Waskewitz J, Zorita E (1996) Estimates of climate change in southern Europe derived from dynamical climate model output. Clim Res 7:129-149

Cubasch U, Allen M, Barthelet P, Beniston M and 29 others (2000) Summary report of the project simulation, diagnosis and detection of anthropogenic climate change (SIDDACLICH). EUR 19310, EU Commission, Brussels

Déqué M, Marquet P, Jones RG (1998) Simulation of climate change over Europe using a global variable resolution general circulation model. Clim Dyn 14:173-189

Ding Y (1991) Advanced synoptics. China Meteorological Press, Beijing

Dümenil-Gates L, Hagemann S, Golz C (2000) Observed historical discharge data from major rivers for climate model validation. MPI Report No. 307, Max Planck Institute for Meteorology, Hamburg

Hagemann S, Dümenil L (1998) Development of a parameterization of lateral discharge for the global scale. Clim Dyn $14: 17-31$

Hagemann S, Dümenil L (1999) Application of a global discharge model to atmospheric model simulations in the BALTEX region. Nordic Hydrol 30:209-230

Hagemann S, Dümenil-Gates L (2001) Validation of the hydrological cycle of ECMWF and NCEP reanalyses using the MPI hydrological discharge model. J Geophys Res 106:1503-1510

Houghton JT, Meira Filho LG, Callander BA, Harris N, Kattenberg A, Maskell K (eds) (1996) Climate change
1995. The science of climate change. Cambridge University Press, Cambridge

Hu ZZ, Latif M, Roeckner E, Bengtsson L (2000a) Intensified Asian summer monsoon and its variability in a coupled model forced by increasing greenhouse gas concentrations. Geophys Res Lett 27:2681-2684

Hu ZZ, Bengtsson L, Arpe K (2000b) Impact of global warming on the Asian winter monsoon in a coupled GCM. J Geophys Res 105:4607-4624

Huang RH, Sun FY (1992) Impacts of the tropical western Pacific on the East Asian summer monsoon. J Meteorol Soc Jpn 70:243-256

Hulme M, Zhao ZC, Jiang T (1994) Recent and future climate change in East Asia. Int J Climatol 14:637-658

IPCC (Intergovernmental Panel on Climate Change) (2001) Climate change 2001: the scientific basis. Contribution of Working Group I to the third assessment report of the IPCC. Houghton JT, Ding Y, Griggs DJ, Noguer M, van der Linden PJ, Xiao D (eds). Cambridge University Press, Cambridge

Ji L, Sun S, Arpe K, Bengtsson L (1997) Model study on the interannual variability of Asian winter monsoon and its influence. Adv Atmos Sci 14:1-22

Jones RG, Murphy JM, Noguer M, Keen AB (1998) Simulation of climate change over Europe using a nested regional model. II: Comparison of driving and regional model responses to a doubling of carbon dioxide. Q J R Meteorol Soc 123:265-292

Kalnay E, Kanamitsu M, Kistler R, Collins W and 18 others (1996) NCEP/NCAR 40-year reanalysis project. Bull Am Meteorol Soc 77:437-471

Kitoh A, Yukimoto S, Noda A, Motoi T (1997) Simulated changes in the Asian summer monsoon at times of increased atmospheric $\mathrm{CO}_{2}$. J Meteorol Soc Jpn 75:1019-1031

Kripalani RH, Kulkarni A (2001) Monsoon rainfall variations and teleconnections over South and East Asia. Int J Climatol 21:603-616

Lal M, Srinivasan G, Cubasch U (1996) Implications of increasing greenhouse gases and aerosols on the diurnal temperature cycle of the Indian subcontinent. Curr Sci 71:746-753

Lal M, Cubasch U, Perlwitz J, Waszkewitz J (1997) Simulation of the Indian monsoon climatology in ECHAM3 climate model: sensitivity to horizontal resolution. Int J Climatol $17: 847-858$

Lehmann EL (1986) Testing statistical hypothesis, 2nd edn. John Wiley \& Sons, New York

Lau KM (1992) East Asian winter monsoon rainfall variability and climate teleconnection. J Meteorol Soc Jpn 70:211-241

Lu E, Chan JCL (1999) A unified monsoon index for South China. J Clim 12:2375-2385

May W, Roeckner E (2001) A time-slice experiment with the ECHAM4 AGCM at high resolution: the impact of horizontal resolution on annual mean climate change. Clim Dyn 17:407-420

New M, Hulme M, Jones PD (2000) Representing twentiethcentury space-time climate variability. Part II: Development of 1901-96 monthly grids of terrestrial surface climate. J Clim 13:2217-2238

Nitta T, Hu ZZ (1996) Summer climate variability in China and its association with $500 \mathrm{hPa}$ height and tropical convection. J Meteorol Soc Jpn 74:425-445

Roeckner E, Arpe K, Bengtsson L, Christoph M and 6 others (1996) The atmospheric general circulation model ECHAM-4: model description and simulation of presentday climate. MPI-Report No. 218, Max Planck Institute for Meteorology, Hamburg 
Roeckner E, Bengtsson L, Feichter J, Lelieveld J, Rodhe H (1999) Transient climate change simulations with a coupled atmosphere-ocean GCM including the tropospheric sulfur cycle. J Clim 12:3004-3032

Rummukainen M (1997) Methods for statistical downscaling of GCM simulations. RMK No. 80, SMHI, Norrköping

Samel AN, Wang WC, Liang XZ (1999) The Monsoon rainband over China and its relationship with the Eurasian circulation. J Clim 12:115-131

Stendel M, Roeckner E (1998) Impacts of horizontal resolution on simulated climate statistics in ECHAM4. MPI Report No. 253, Max Planck Institute for Meteorology, Hamburg

Tao S, Chen L (1987) A review of recent research on the East Asian monsoon in China. In: Chang CP (ed) Monsoon

Editorial responsibility: Hans von Storch,

Geesthacht, Germany meteorology. Oxford monographs on geology and geophysics, Vol. 7. Oxford University Press, Oxford, p 60-92

Wang S, Ye D (1993) Analysis of the global warming during the last one hundred years. In: Ye D, Taroh M, Zeng $Q_{\text {, }}$ Huang R, Zhang R (eds) Climate variability. China Meteorological Press, Beijing, p 23-32

Wang S, Gong D, Zhu J (2001) Twentieth-century climatic warming in China in the context of the Holocene. The Holocene 11:313-321

Wilby RL, Wigley TML (1997) Downscaling general circulation model output: a review of methods and limitations. Prog Phys Geogr 21:530-548

Yasunari T (1991) The monsoon year: a new concept of the climatic year in the tropics. Bull Am Meteor Soc 72: $1331-1338$

Submitted: October 8, 2002; Accepted: March 17, 2003

Proofs received from author(s): June 2, 2003 